\title{
PRODUÇÃO DE BIOMASSA POR CULTIVO HETEROTRÓFICO DA CIANOBACTÉRIA APHANOTHECE MICROSCOPICA NÄGELI EM ESGOTO DOMÉSTICO
}

\author{
R. G. BASTOS ${ }^{1}$, A. PULSHEN ${ }^{1}$; C. F. SOUZA ${ }^{1}$; D. SILVA ${ }^{1}$, M. I. QUEIROZ ${ }^{2}$ \\ ${ }^{1}$ Universidade Federal de São Carlos, Centro de Ciências Agrárias \\ E-mail para contato: reinaldo@cca.ufscar.br \\ ${ }^{2}$ Fundação Universidade Federal de Rio Grande, Escola de Química e Alimentos
}

\begin{abstract}
RESUMO - As cianobactérias vêm sendo utilizadas na remoção de matéria orgânica e nutrientes de efluentes. De fato, como algumas linhagens desses micro-organismos são passíveis de metabolismo heterotrófico, pode ser indicada a produção de biomassa a partir de águas residuárias industriais ou domésticas com turbidez elevada, a qual limita a penetração de luz e a aplicação de sistemas autotróficos. Nesse sentido, o objetivo da pesquisa foi avaliar o cultivo da cianobactéria Aphanothece microscopica Nägeli em esgoto doméstico. Os experimentos foram conduzidos em bateladas de 30 horas, sendo utilizado esgoto doméstico coletado na entrada da estação experimental de tratamento e reúso agrícola do CCA/UFSCar. Os resultados indicaram velocidades específicas de crescimento máximas de $0,018 \mathrm{~h}^{-1}$, com consumo de DQO e $21 \mathrm{mg} \mathrm{L}^{-1} \mathrm{~h}^{-1}$ (ordem zero), limitado pelo nitrogênio a uma taxa de $0,04 \mathrm{~h}^{-1}$ (primeira ordem). As máximas remoções de DQO, nitrogênio e fósforo obtidas foram 53, 67 e $92 \%$, respectivamente.
\end{abstract}

\section{INTRODUÇÃO}

O uso de microalgas na purificação de águas residuárias industriais e domésticas vem sendo estudado como alternativa aos processos convencionais de despoluição (Martínez et al., 2000). Estes processos apresentam como grande vantagem o aproveitamento da biomassa gerada na produção de proteínas unicelulares, compostos celulares como pigmentos ou obtenção de biodiesel através da transesterificação do óleo microalgal. Nesse sentido, Aphanothece microscopica Nägeli é uma cianobactéria muito estudada devido ao seu elevado teor protéico ("single cell protein") e por ser passível de cultivo no efluente da parboilização do arroz (Bastos et al., 2004; Queiroz et al., 2007) e de indústrias de pescado visando reúso das águas (Manetti, 2008). Queiroz et al. (2001), avaliando o potencial de remoção de nitrogênio e matéria orgânica do efluente da parboilização do arroz pela Aphanothece microscopica Nägeli, constaram máximos de remoção em 24 horas de cultivo a 3 klux e $30^{\circ} \mathrm{C}$. Segundo Queiroz et al. (2002), esta cianobactéria foi capaz de desenvolver-se no escuro a partir da matéria orgânica presente neste efluente. Mais recentemente, este micro-organismo vem sendo estudado em fotobiorreatores para 


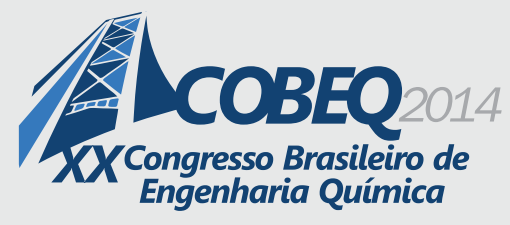

19 a 22 de outubro de 2014

Florianópolis/SC

o sequestro de carbono (Jacob-Lopes et al., 2008) e avaliado quanto ao conteúdo de lipídios e perfil de ácidos graxos da biomassa, visando a produção de biodiesel (Francisco et al., 2010).

O tratamento de águas residuárias através do cultivo heterotrófico de células livres e imobilizadas de microalgas e cianobactérias é promissor tanto para a remoção de nutrientes como matéria orgânica solúvel (Bastos et al., 2004; de-Bashan e Bashan, 2010; Perez-Garcia et al., 2011). No caso da utilização de águas residuárias industriais ou domésticas, devido à sua turbidez geralmente elevada, a limitada penetração de luz reduz a eficiência dos cultivos autotróficos, sendo recomendada a utilização de micro-organismos passíveis de crescimento via consumo ou assimilação de moléculas orgânicas, com consequente redução da DBO e nutrientes. Bhatnagar et al (2011) comprovaram crescimento mixotrófico de Chlamydomonas globosa, Chlorella minutissima e Scenedesmus bijuga em meio suplementado com diferentes fontes de carbono (glicose, sacarose, acetato de sódio, metanol, glicerol) e em efluentes urbano e agroindustrial (frigorífico de aves). Wu et al (2012) avaliaram o cultivo de Clamydomonas sp. e Desmodesmus $s p$. em fotobiorreator usando efluente do parque industrial de Taichung, Taiwan. Os melhores resultados indicaram remoções de $100 \% \mathrm{NH}_{4}{ }^{+}-\mathrm{N}$ e $\mathrm{NO}_{3}{ }^{-}-\mathrm{N}$ e $33 \%$ de $\mathrm{PO}_{4}{ }^{-3}-\mathrm{P}$ para Clamydomonas, obtendo 18,4\% em lipídios na biomassa, um promissor resultado visando a subsequente produção de biodiesel. Prathima Devi et al. (2012) estudaram o cultivo heterotrófico misto de microalgas em efluente doméstico suplementado com diferentes nutrientes e glicose, apresentando alta produção de biomassa e remoção de nutrientes. Os autores sugerem a produção de microalgas dos gêneros Chlorella e Scenedesmus (Desmodesmus) a partir de águas residuárias visando o aproveitamento da biomassa para obtenção de biodiesel.

Efluentes domésticos e municipais compreendem uma mistura complexa de sólidos solúveis e em suspensão. A maioria destes efluentes apresenta matéria orgânica solúvel mesmo após o tratamento secundário biológico, o que sugere a presença de fontes de carbono prontamente disponíveis para bactérias, mas de difícil assimilação por microalgas (Perez-Garcia et al., 2011). Entretanto, mesmo que não se obtenham remoções de matéria orgânica e nutrientes comparáveis aos processos convencionais de tratamento de efluentes, o cultivo levaria a geração de biomassa com valor agregado e adequaria a composição da água visando seu reúso agrícola. Nesse sentido, o Centro de Ciências Agrárias (CCA) da Universidade Federal de São Carlos (UFSCar) em Araras/SP vem realizando pesquisas sobre reúso agrícola do esgoto doméstico gerado no próprio Campus. O CCA apresenta uma estação piloto de tratamento e reúso de água que consiste de uma unidade de tanque séptico, um filtro anaeróbio de fluxo ascendente, um tanque com microalgas e/ou cianobactérias, seguido de um sistema de leitos cultivados de macrófitas para a adequação final do efluente. O efluente tratado vem sendo avaliado quanto à sua disposição no solo, qualidade e aplicabilidade em culturas de alface e rabanete (Mendonça et al, 2013; Mendes et al., 2013).

Neste contexto, o presente trabalho teve como objetivo avaliar o potencial de crescimento e remoção de DQO, nitrogênio e fósforo de esgoto doméstico do CCA/UFSCar pela cianobactéria Aphanothece microscopica Nägeli. 


\section{MATERIAL E MÉTODOS}

\subsection{Inóculo}

A cianobacéria A. microscopica foi cedido pelo Laboratório de Biotecnologia da Escola de Química e Alimentos da FURG, sendo mantida em meio de cultura Braun - Grunow (BGN) (Ripka et al., 1979) no Laboratório de Microbiologia Aplicada e Controle (LABMAC/DTAiSER/CCA) da UFSCar. Para os ensaios com a água residuária foi utilizada um inóculo de aproximadamente $700 \mathrm{mg} \mathrm{L}^{-1}$, que corresponde a ordem de $10^{6}$ células $\mathrm{mL}^{-1}$.

\subsection{Ensaios}

A biomassa foi separada do meio de manutenção BGN por centrifugação a $3000 \mathrm{rpm}$ por 5 minutos em centrífuga Elcesa II 206 BL. O efluente coletado na estação piloto de tratamento e reúso de água do CCA/UFSCar foi autoclavado e homogeneizado com o inóculo de $A$. microscopica, sendo distribuídos em Frascos Erlenmeyers de $125 \mathrm{~mL}$. Os frascos foram protegidos da luz e os ensaios conduzidos em incubadora com agitação orbital (Tecnal ${ }^{\circledR}$ TC-420) a $150 \mathrm{rpm}$. A amostra de esgoto utilizada apresentou $\mathrm{pH} 7,1$, demanda química de oxigênio (DQO) de $1224 \mathrm{mg} \mathrm{L}^{-1}$, nitrogênio total (NT) de $30 \mathrm{mg} \mathrm{L}^{-1}$ e fósforo (P) 2,1 $\mathrm{mg} \mathrm{L}^{-1}$. Os ensaios foram monitorados a cada três horas com determinação dos perfis de concentração celular e substratos em 30 horas.

\subsection{Análises}

A concentração da biomassa foi determinada por gravimetria após filtração de volume conhecido da suspensão amostrada durante os cultivos em filtro $0,22 \mu \mathrm{m}$ e secagem a $105^{\circ} \mathrm{C}$ por 24 horas (APHA, 2005). Com estes dados, foram obtidas curvas de crescimento, sendo calculadas velocidades específicas de crescimento máximas.

A DQO foi determinada pelo método colorimétrico em refluxo fechado, sendo as amostras acrescidas de solução digestora $\left(\mathrm{H}_{2} \mathrm{SO}_{4}+\mathrm{K}_{2} \mathrm{Cr}_{2} \mathrm{O}_{7}\right)$ digeridas durante 2 horas em bloco digestor $\mathrm{HACH}^{\circledR}$ DRB200 a $150^{\circ} \mathrm{C}$, com posterior leitura da absorbância em espectrofotômetro HACH ${ }^{\circledR}$ DR 5000 a $600 \mathrm{~nm}$. A curva-padrão para análise de DQO foi construída utilizando biftalato de potássio.

O teor de nitrogênio total (NT) do efluente foi determinado através do método da digestão com persulfato de potássio e hidróxido de sódio, em bloco digestor $\mathrm{HACH}^{\circledR}$ DRB200 durante 30 minutos, com leituras a $410 \mathrm{~nm}$ em Espectrofotômetro HACH ${ }^{\circledR}$ DR 5000.

$\mathrm{O}$ teor de fósforo do meio líquido $(\mathrm{P})$ foi determinado por digestão da amostra com ácido sulfúrico, seguido de reação colorimétrica usando kit LABORLAB® e leitura em espectrofotômetro a $340 \mathrm{~nm}$. 


\subsection{Avaliação cinética}

A partir dos valores de concentração celular (X), e dos substratos (S) DQO e NT calculouse as velocidades específicas de crescimento $\left(\mu_{\text {máx }}\right)$ pela integração da Equação 1 e constantes cinéticas de consumo de DQO $\left(\mathrm{k}_{\mathrm{DQO}}\right)$ e NT $\left(\mathrm{k}_{\mathrm{NT}}\right)$ através da Equação 1, determinando-se a ordem de reação "n".

$$
\begin{aligned}
& \mu_{x}=\frac{1}{X} \frac{d(X)}{d t} \\
& r_{S}=k S^{n}
\end{aligned}
$$

Os rendimentos dos substratos (DQO, NT e P) em biomassa $\left(\mathrm{Y}_{\mathrm{X} / \mathrm{S}}\right)$ foram calculados pela relação das taxas de crescimento e consumo, ou seja, pela inclinação da curva biomassa $v s$ substratos (S), de acordo com a Equação 3:

$$
Y_{X / S}=-\frac{d(X)}{d(S)}
$$

\section{RESULTADOS E DISCUSSÃO}

A Figura 1 apresenta os perfis de biomassa e DQO do esgoto doméstico do CCA/UFSCar no cultivo de A. microscopica. De acordo com os resultados obtidos, percebe-se uma fase de adaptação de crescimento até aproximadamente 12 horas, seguida de uma etapa de crescimento vigoroso, que leva a uma queda brusca da DQO do meio. Este perfil de crescimento se traduz em uma velocidade específica máxima de $0,018 \mathrm{~h}^{-1}$, conforme apresentado na Tabela 1 . A velocidade de crescimento é da mesma ordem de grandeza de outras pesquisas com microalgas em efluentes domésticos, embora obtida em menores tempos de batelada (Xin, et al., 2010a; Xin, et al, 2010b).

Além disso, há um rendimento global médio de 0,66 mg de biomassa por $\mathrm{mg}$ de DQO, indicando uma elevada conversão da matéria orgânica do efluente em células, com remoção máxima de DQO de 54\%. A curva de consumo de DQO sugere uma cinética de ordem zero, ou seja, sem limitação, com uma constante de $21 \mathrm{mg}(\mathrm{L} \mathrm{h})^{-1}$. Estes resultados diferem dos obtidos por Queiroz et al. (2007) para esta mesma cianobactéria em efluente da parboilização do arroz, onde o consumo de ordem zero foi válido apenas para altos valores de DQO. Além disso, estes mesmos autores reportam rendimentos médios de $0,17 \mathrm{mg}$ de biomassa por $\mathrm{mg}$ de DQO, o que indica um crescimento mais adequado e não limitado a quantidade de matéria orgânica a partir do esgoto doméstico. 


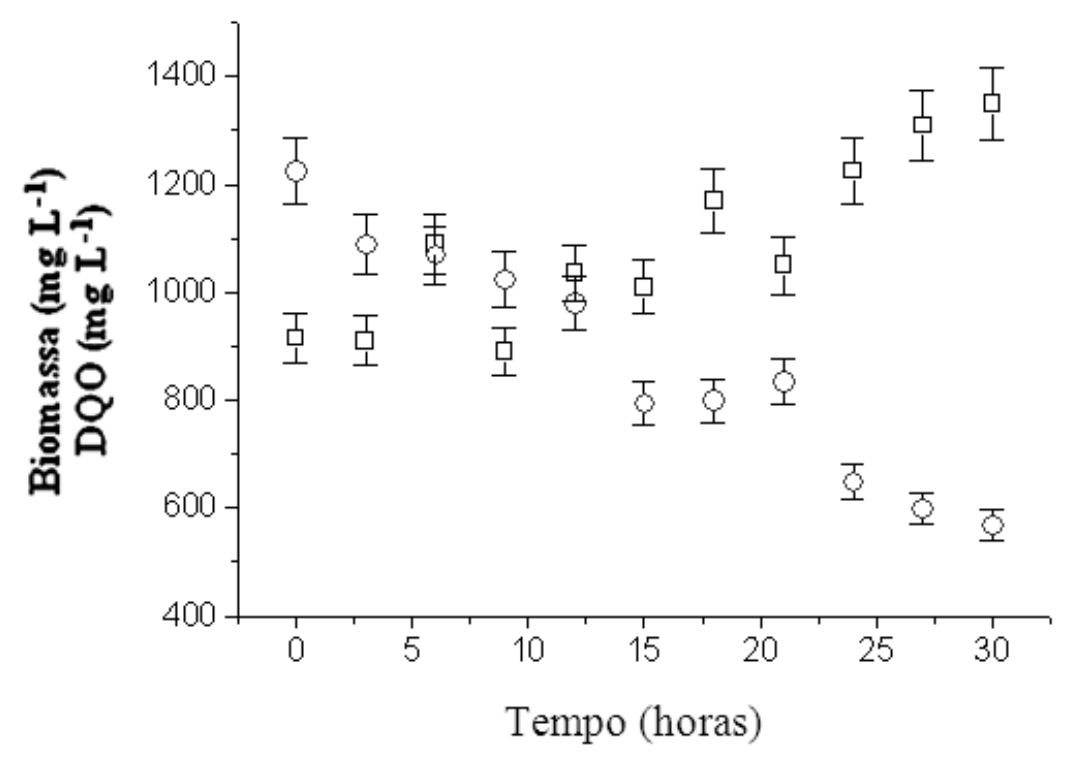

Figura 1 - Perfis de biomassa ( $\square$ ) e DQO (O) no cultivo de Aphanothece microscopica Nägeli em esgoto doméstico do CCA/UFSCar

De acordo com a Figura 2, percebe-se que o consumo de nitrogênio segue uma cinética de primeira ordem com constante cinética de $0,04 \mathrm{~h}^{-1}$ (Tabela 1), o que sugere que o nitrogênio é o substrato limitante para o cultivo desta cianobactéria neste efluente. Apesar disto, quanto aos nutrientes, obteve-se remoções máximas de 67 e $92 \%$ de nitrogênio e fósforo, respectivamente.

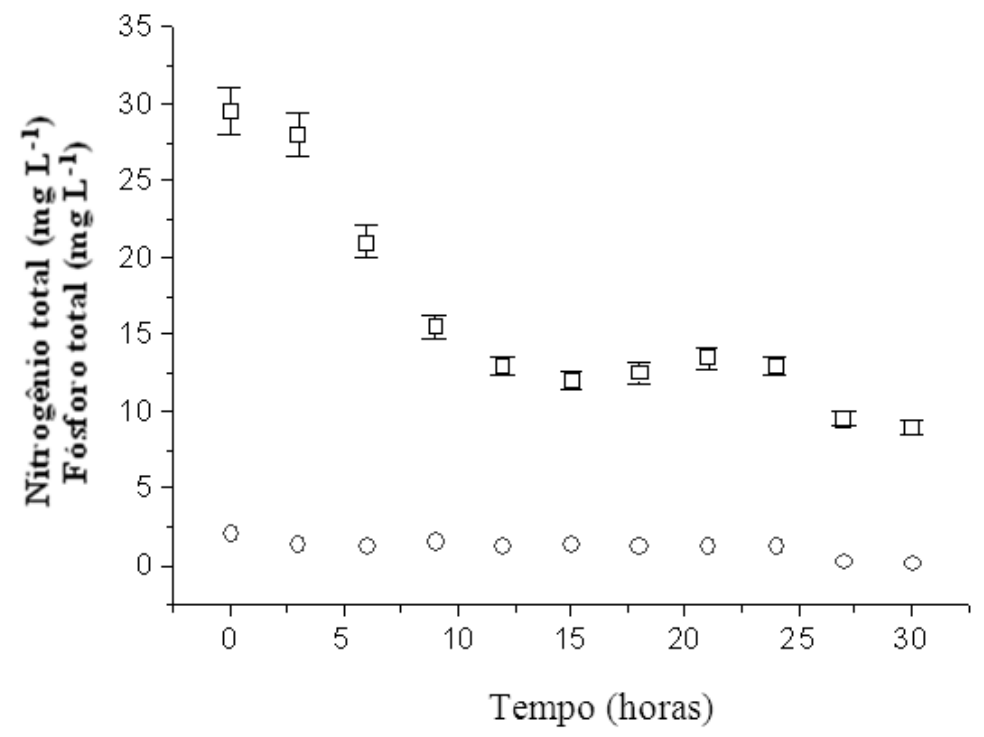

Figura 1 - Perfis de nitrogênio ( $\square$ ) e fósforo (O) no cultivo de Aphanothece microscopica Nägeli em esgoto doméstico do CCA/UFSCar 
Com relação ao nitrogênio, apesar da remoção elevada, de acordo com Bich et al (1999), outros mecanismos são capazes de eliminar as formas nitrogenadas no meio em cultivos com aeração forçada, tais como o arraste na corrente de ar, volatilização da amônia, absorção e sedimentação. Quanto à remoção de fósforo, o consumo aproximado de 100\% deste nutriente está de acordo com o que vem sendo reportado na literatura para outras microalgas nestes efluentes (Xin, et al., 2010b). Apesar disto, tal consumo ocorre em menos tempo, na ordem de horas, o que sugere produtividade maior para A. microscopica e viabilidade de cultivo desta cianobactéria em efluentes domésticos.

Tabela 1 - Parâmetros cinéticos do cultivo de A. microscopica em esgoto doméstico do CCA/UFSCar

\begin{tabular}{cc}
\hline Parâmetro & Valor \\
\hline$\mu_{\text {máx }}$ & $0,018 \mathrm{~h}^{-1}$ \\
$k_{D Q O}$ & $21 \mathrm{mg}(\mathrm{L} . \mathrm{h})^{-1}$ \\
$k_{N T}$ & $0,04 \mathrm{~h}^{-1}$ \\
\hline
\end{tabular}

\section{CONCLUSÕES}

Nas condições experimentais foi possível concluir que os parâmetros cinéticos de crescimento e consumo de nitrogênio e DQO indicam a viabilidade do cultivo da cianobactéria Aphanothece microscopica Nägeli em efluente doméstico do CCA/UFSCar.

\section{REFERÊNCIAS}

APHA - American Public Health Association. Standard methods for the examination of water and wastewater. $21^{\mathrm{a}}$ ed. Washington: AWWA/APHA/WEF, 2005.

BASTOS, R.G.; QUEIROZ, M.I.; ALMEIDA, T.L.; BENERI, R.L.; ALMEIDA, R.V.; PADILHA, M. Remoção de nitrogênio e matéria orgânica do efluente da parboilização do arroz por Aphanothece microscopica Nägeli na ausência de luminosidade. Revista da Engenharia Sanitária e Ambiental, v. 9, n. 2, p.112-116, 2004.

BICH, N.N., YAZIZ, M.I., KAKTI, N. Combination of Chlorella vulgaris and Eichhornia crassipes for wastewater nitrogen removal. Water Research 33 (10), 2357-2362, 1999.

BHATNAGAR, A.; CHINNASAMY, S.; SINGH, M.; DAS, K.C. Renewable biomass production by mixotrophic algae in the presence of various carbon sources and wastewaters. Applied Energy, v. 88, n. 10, p. 3425-3431, 2011. 


\section{9 a 22 de outubro de 2014 \\ Florianópolis/SC}

MARTÍNEZ, M.E., SÁNCHEZ, S., JÍMENEZ, J.M., YOUSFIS, F.E.; MUÑOZ, L.Nitrogen and phosphorus removal from urban wastewater by the microalga Scenedesmus obliquus.

Bioresource Technology, v. 73, p. 263-272, 2000.

MENDES, P. E. F. ; SOUZA, C. F. ; FERREIRA, A. J. D. ; MATTOS, L. F. A. Água de reúso na agricultura: implicações agronômicas e ambientais em rabanate (Raphanus sativus L.). In: Anais do XLII Congresso Brasileiro de Engenharia Agrícola (CONBEA), Fortaleza, 2013.

MENDONCA, T. G. ; URBANO, V.R. ; BASTOS, REINALDO GASPAR; SOUZA, C.F. Efeitos da aplicação de água de reúso no solo cultivado com alface (Lactuca sativa L.). In: Anais do XLII Congresso Brasileiro de Engenharia Agrícola, Fortaleza, 2013.

PEREZ-GARCIA, O.; ESCALANTE, F.M.E.; DE-BASHAN, L.E.; BASHAN, Y. Heterotrophic cultures of microalgae: Metabolism and potential products. Water Research, v. 45, p. 11-36, 2011.

PRATHIMA DEVI, M.; VENKATA SUBHASH, G.; VENKATA MOHAN, S. Heterotrophic cultivation of mixed microalgae for lipid accumulation and wastewater treatment during sequential growth and starvation phases: Effect of nutrient supplementation. Renewable Energy, v. 43, p. 276-283, 2012.

QUEIROZ, M. I.; BASTOS, R.G.; BENERI, R.L.; ALMEIDA, R.V. Evaluación del crecimiento de la Aphanothece microscopica Nägeli en las aguas residuales de la parbolización del arroz. Revista Información Tecnologica, Chile,v. 13, n. 1, p. 61-65, 2002.

RIPPKA, R.; DERUELLES, J.; WATERBURY, J.B.; HERDMAN, M.; STANIER, R.Y. Generic Assignments Strain Histories and Properties of Pure Cultures of Cyanobacteria. Journal of General Microbiology. Great Britain, n.111. p.1-61, 1979.

WU, L.F.; CHEN, P.C.; HUANG, A.P.; LEE, C.M. The feasibility of biodiesel production by microalgae using industrial wastewater. Bioresource Technology, v. 113, p. 14-18. 2012.

XIN, L.; HONG-YING, H; KE, G.; YING-XUE, S. Effects of different nitrogen and phosphorus concentration of growth uptake, and lipid accumulation of a freshwater microalga Scenedesmus sp. Bioresouce Technology, v. 101, p. 5494-5500, 2010a.

de-Bashan, L. E., \& Bashan, Y. (2010). Immobilized microalgae for removing pollutants: review of practical aspects. Bioresource Technology, 101(6), 1611-27.

doi:10.1016/j.biortech.2009.09.043

Xin, L., Hong-Ying, H., \& Jia, Y. (2010). Lipid accumulation and nutrient removal properties of a newly isolated freshwater microalga, Scenedesmus sp. LX1, growing in secondary effluent. New Biotechnology, 27(1), 59-63. doi:10.1016/j.nbt.2009.11.006

Xin, L., Hong-ying, H., Ke, G., \& Jia, Y. (2010). Growth and nutrient removal properties of a freshwater microalga Scenedesmus sp. LX1 under different kinds of nitrogen sources. Ecological Engineering, 36(4), 379-381. doi:10.1016/j.ecoleng.2009.11.003 
QUEIROZ, M.I.; KOETZ, P.R.; TREPTOW, R.O. The Nagele microscocal Aphanothece potential in the production of the single-cell protein from the remaining water. In: CHAMES, S.W., CÁNOVAS-BARBOSA, G.V.; AGUILERA, J.M. (Ed.) Proceddings of the eighth International Congress on Engineering and Food (ICEF 8), Pennsylvania, USA, p. 2027-2031, 2001.

QUEIROZ, M.I.; LOPES, E.J.; ZEPKA, L.Q.; BASTOS, R.G.; GOLDBECK, R. The kinetics of the removal of nitrogen and organic matter from parboiled rice effluent by cyanobacteria in a stirred batch reactor. Bioresource Technology, v. 98 (11), p.2163-2169, 2007.

MANETTI, A.G.S. Avaliação do reuso da água residuária oriunda de uma indústria processadora de pescado utilizando Aphanothece microscopica Nägeli. Mestrado em Engenharia e Ciência de Alimentos. Fundação Universidade Federal do Rio Grande, Rio Grande, RS. 85p. 2008.

JACOB-LOPES, E.; SCOPARO, C.H.G.; FRANCO, T.T. Rates of $\mathrm{CO}_{2}$ removal by Aphanothece microscopica Nägeli in tubular photobioreactors. Chemical Engineering and Processing, v. 47, p.1365-1373, 2008.

FRANCISCO, E.C.; NEVES, D.B.; JACOB-LOPES, E.; FRANCO, T.T. Microalgae as feedstock for biodiesel production: Carbon dioxide sequestration, lipid production and biofuel quality. Journal of Chemical Technology and Biotechnology, v. 85, p. 395-403, 2010. 